\title{
Research on the Main Problems and the Solutions in the Laboratory Construction in Newly - built Undergraduate Colleges
}

\author{
Tao Song \\ ${ }^{1}$ Chongqing University of Education, Chongqing, China, 400065
}

Keywords: New Undergraduate Colleges; Laboratory Construction; Main Problems; Solutions

\begin{abstract}
University laboratory is the main place for the cultivation of applied talents, but also the place where the financial and material resources are relatively concentrated in colleges and universities, the birthplace of scientific research project development. However, for the new undergraduate colleges, there are still some problems in the laboratory construction, such as the lack of adequate financial support for the construction of the laboratory, the technical team of professional low, poor quality of experimental teaching and many other issues, so this article on the new. This paper analyzes the existing problems in the laboratory construction of the undergraduate colleges and puts forward the corresponding countermeasures and approaches to solve the problem, and provides reference for the laboratory construction so as to facilitate the reform of the experimental teaching in colleges and universities.
\end{abstract}

\section{Introduction}

With the development of higher education and the importance of the state to the work of higher education, the new undergraduate colleges are also developing, but in the development process by many factors, including laboratory construction is its main constraint [1]. In order to promote the development of colleges and universities and promote the smooth development of scientific research projects and experimental teaching work, it is necessary to improve the level of laboratory construction and increase the level of laboratory construction and laboratory development. Construction of capital investment and the use of advanced management concepts improve the level of teaching and research capacity.

\section{Current Situation of Laboratory Construction in Newly - built Universities}

The construction of university laboratory reflects the level of scientific research and teaching strength of the school. The laboratory is an important site for scientific research and experimental teaching. It is of great significance and value to the construction of laboratory in new undergraduate colleges. At the same time, the university laboratory is also an important place to cultivate students' ability of innovation, thinking ability, practical ability and problem-solving ability, which has a direct influence on the quality of university personnel training. The construction of the laboratory in the newly established undergraduate colleges is the key to improve the competitiveness of colleges and universities. Therefore, it is necessary to pay attention to the construction of the laboratory and continuously improve the quality of the laboratory construction and the construction level so that the essential functions of the laboratory can be fully realized. Undergraduate colleges and universities to carry out quality education, so that the quality of teaching to meet the development needs of the community to develop professional application of talent has important practical significance and value.

At present, Chinese colleges and universities in the laboratory construction progress is bigger, and the construction process is fast, but the new undergraduate colleges, in the laboratory construction in the hardware facilities, software technology, management system and so on with the 
international advanced laboratory construction There is a certain gap [2]. With the continuous expansion of the scale of running a university, the gradual improvement of the level of science and technology, these laboratories have had serious obstacles to the development of colleges and universities. In order to meet the trend of the development of the times and the development trend, to cultivate the needs of social development, high-quality professional application talents is the main goal of new undergraduate colleges, so in the laboratory construction should strengthen its attention. According to the current problems in the laboratory construction, we should combine the actual situation of laboratory construction, and from the hardware construction and software construction of these two aspects of laboratory construction and innovation, and constantly improve the laboratory management system, to strengthen the experiment the training of personnel training efforts to improve the quality of experimental teaching.

\section{The Main Problems in the Construction of Laboratory in Newly - built Undergraduate Colleges}

The Number of Scientific Research Laboratories Is Limited. The level of scientific research in colleges and universities reflects the strength of running a university in a certain extent, and it is very important for the scientific research ability of the new undergraduate colleges. To improve the scientific research ability of the new undergraduate colleges, the university actively encourages teachers to apply for scientific research projects and actively participate in and put into scientific research projects, the academic in-depth research and innovation, scientific research laboratory is the talent innovation ability to cultivate an important place. But in the new undergraduate colleges in the construction of scientific research laboratories less, it is difficult to meet the needs of teachers and students to carry out scientific research work, such as a university building a 8-tier laboratory, which in addition to inorganic chemistry laboratory, environmental monitoring laboratory, Instrumentation laboratory, the proportion of scientific research laboratories less, some of the laboratory use of low efficiency, most of which are not installed in the laboratory some of the necessary infrastructure, such as sinks, test benches, etc., leading to scientific research projects can not start normal [3]. At the same time, due to the lack of scientific research funds in colleges and universities, resulting in the lack of financial support for the construction of scientific research laboratories, resulting in the lack of scientific research laboratory construction, teachers of scientific research work to restrict, but also directly affect the quality of graduate design.

Large Equipment Idle. In the construction of university laboratories, large-scale equipment is an essential equipment, scientific research work and experimental teaching is an important foundation and material security, the level of teaching and school scale to measure the important indicators. With the increasing emphasis on the construction of university laboratories, the number of colleges and universities in the large-scale equipment procurement increased significantly, Management difficulties, in the new undergraduate colleges and universities in the large-scale equipment and equipment problems are common, such as attention to large-scale equipment procurement work, but not the end of large-scale equipment for efficient use, the use of low efficiency, the operation and maintenance of equipment Work is not in place, leading to large laboratory equipment idle, or in the use of equipment and equipment in the process of failure, thus affecting the scientific research and experimental teaching quality and efficiency [4]. In addition, the equipment is managed by a dedicated department, but it is difficult to share equipment and equipment in other departments of the university. The equipment utilization and utilization efficiency are low and cannot give full play to its role and value.

The Laboratory Management System. With the development and progress of the times, most of the laboratory management philosophy and management system have been innovative and perfect, but in the new undergraduate colleges laboratory still use the traditional laboratory management model and management thinking, It is difficult to meet the requirements of reform and development of colleges and universities, so establish a sound laboratory management system in order to ensure the normal development and effective development of laboratory work in colleges and universities, through the management system to ensure the smooth development of laboratory 
work [5]. At present, the new undergraduate laboratory management system in the prevalence of the system difficult to implement the problem, in order to improve the quality of laboratory construction and management level, it is necessary to strengthen the development of the system, and clear the scope of the system, the laboratory equipment real-time monitoring and inspection in order to facilitate the timely detection of the problem, while the system is constantly revised and improved to ensure that the laboratory system of scientific and standardized to ensure that experimental teaching and scientific research work in an orderly manner.

\section{Solutions to the Construction of Laboratory in Newly - built Undergraduate Colleges}

Management System Innovation. With the development and innovation of the times, in the construction of university laboratories also need to innovate the laboratory management system, so that with the times, the use of advanced management concepts, new undergraduate colleges should actively learn advanced management at home and abroad concept, the current management of the use of the concept of innovation, such as the use of integrated production and research management model or open laboratory management model. In addition, in the laboratory management should also pay attention to technology investment, in the information age, to the traditional laboratory construction in the introduction of advanced technology, and actively build information technology laboratory, and the laboratory fine and digital management [6] The With the popularization of information technology in people's life, colleges and universities in the laboratory construction and management can also use computer technology or Internet technology, the establishment of laboratory management system, the laboratory for efficient management, laboratory management staff through computer technology will Laboratory equipment information, laboratory subjects, resource use and so on are input to the computer, and with the campus network, the laboratory information resources are transparent and open, college teachers and students can query the campus network laboratory related information, and make an appointment to the laboratory. In the experimental teaching, for some of the higher risk and toxic experiments, through the construction of simulation laboratory to carry out teaching work, not only can achieve the teaching effect, but also reduce the laboratory management pressure.

Strengthen the Training of Experimental Personnel. The main purpose of the construction of the new undergraduate colleges is to cultivate practical talents with practical ability and innovative ability. In the laboratory construction, we should also pay attention to strengthen the training of experimental personnel, but in the new undergraduate institutions because of the management system problem, and did not put the experimental technical staff and experimental teachers into the teachers, the unified management and coordination, resulting in a large number of experimental personnel loss, or experimental staff work enthusiasm is low. Experimental staff as the main project of the experimental project, directly reflects the level of laboratory business and management quality, so to improve the level of laboratory construction, it is necessary to strengthen the training of experimental personnel to improve the overall level of professional and technical personnel and business level and the establishment of incentives, the enthusiasm of the experimental staff to fully mobilize [7]. In addition, we should pay attention to the training of experimental personnel, colleges and universities to increase the intensity of training funds for experimental personnel, and actively encourage the experimental staff to carry out further study, and regularly organize a variety of skills training and travel visits, inspection, so that the experimental staff constantly updated itself. The level of knowledge, broaden their horizons, the contemporary new things and technology to master, so as to better into the laboratory work, for the school research and experimental teaching work to provide services. At the same time, the new undergraduate colleges in the laboratory personnel aging and the lack of the situation, so colleges and universities should be from multiple channels and multi-directional recruitment of experimental personnel, such as technical undergraduate life graduate students to recruit, or recruit some enterprises rich technical experience of technical staff to meet the needs of laboratory management [8].

Increase the Management of Large Equipment and Equipment. University laboratories in the procurement of large-scale equipment should be considered in the process of social services, 
experimental teaching and research, capital and other factors, and in accordance with the priorities of the use of higher frequency equipment and equipment procurement, but also to do the equipment The procurement records work, to avoid duplication of procurement, and cause the instrument idle situation. In the procurement of equipment, but also to consider the advanced nature of the equipment, but not too blind pursuit of advanced nature and ignores the quality of equipment, to make the best use and value for money. Secondly, in the equipment and equipment management must first clear the management of equipment and equipment, establish a sound equipment management system, but also on the management concept of innovation, the use of computer software to build equipment and equipment management system, the laboratory of large equipment Centralized management, at the same time in the equipment and equipment management system for the use of equipment to publicize, in order to teachers and students query, the establishment of equipment and equipment sharing platform for large-scale equipment can be better management [9]. In addition, colleges and universities should also set up specialized equipment management department, and by the personal care, laboratory staff need to undergo professional training, advanced equipment and operating procedures and working principles have a certain understanding and mastery, and skilled operation of the instrument, usually to strengthen the operation of the equipment and equipment testing and maintenance, when the instrument fails in the case of the need for immediate repair, to avoid long-term idle or delayed maintenance caused by the phenomenon of equipment scrapped. Part of the new undergraduate colleges due to lack of funds in the laboratory construction due to financial constraints, large equipment and equipment maintenance costs, resulting in equipment and equipment maintenance difficult situation, colleges and universities can strengthen cooperation with enterprises, scientific research projects to jointly declare, and to provide enterprises with paid inspection services and equipment for the use of equipment for large-scale equipment operation and maintenance management to provide financial support, so that the value of large-scale equipment and investment benefits to fully play out.

\section{Conclusion}

The main purpose of the laboratory construction of the new undergraduate colleges is to cultivate the experimental talents. In the experimental teaching and research projects, the laboratory plays an important carrier of the project. The quality of the laboratory construction is directly related to the efficiency and quality of the scientific research project and experiment teaching. And the impact of personnel training objectives has a certain impact, colleges and universities will strengthen the importance of the construction of the laboratory. At present, there are still some problems in the construction of the laboratory, such as the problem of laboratory management system, the construction of scientific research laboratory, the large equipment and equipment idle, seriously hampered the development of experimental work in colleges and universities, but also affected the development of colleges and universities. Therefore, this paper based on the status quo of laboratory construction and the existence of specific recommendations and comments in order to improve the level of laboratory construction.

\section{References}

[1] Zhu Hai-yan, Chen Peng-xiang, Li Cheng. New Advances in Laboratory Construction and Management of Newly-built Undergraduate Colleges[J]. Journal of Experimental Technology and Management, 2012, 29 (03): 196-198.

[2] He Ye. Analysis of the Construction of Sports Human Science Laboratory in Newly-built Undergraduate Colleges [J].Journal of Laboratory Research and Exploration, 2012, 31 (06): 199-202.

[3] Tong Man-xia. Study on Laboratory Construction and Experimental Teaching of Chemistry Specialty in Newly-built Undergraduate Colleges [J].Journal of Longyan University, 2010,28 (05): 112-114 (in Chinese) 
[4] Li Cheng. On the development of laboratory construction in new undergraduate colleges and obstacles[J]. Heilongjiang Higher Education Research, 2003, (05): 72-74.

[5] Tan Afan, Yue Zhou. Study on the optimization and reconstruction of laboratory construction in newly built local colleges and universities [J]. Journal of Hunan Institute of Humanities and Science, 2014, (06): 117-119.

[6] Tian Jing, Luo Tong, Luo Huafeng, Zou Taihe. Construction and teaching of virtual simulation laboratory in new undergraduate colleges[J]. Journal of Experimental Science and Technology, 2015,13 (06): 219-222 + 228.

[7] Yang Suxiao. Local new undergraduate colleges engineering management professional laboratory construction research [J]. Science and Technology Information, 2015, 13 (26): $162+$ 164.

[8] Lu Mingning.Study on the laboratory construction of the newly established undergraduate colleges in ethnic areas - Taking the construction of Xichang College of Economics and Management as an example [J]. Journal of Xichang College (Natural Science Edition), 2014,28 (03): 139-142

[9] Lu Fucai. Construction of new undergraduate colleges and universities to explore the research and research[J]. Science and Education (later), 2017, (06): 55-57. 